\title{
ANALISIS TINGKAT PERTUMBUHAN PENERIMAAN PAJAK PENGAMBILAN BAHAN GALIAN GOLONGAN C DI KABUPATEN KEPULAUAN SANGIHE
}

\author{
Jessica Lianita Agnelleide Loong ${ }^{1}$, Treesje Runtu ${ }^{2}$, Meily Y. B. Kalalo ${ }^{3}$ \\ 1,2,3 Jurusan Akuntansi, Fakultas Ekonomi dan Bisnis, Universitas Sam Ratulangi, Jl. Kampus Bahu, Manado, \\ 95115, Indonesia \\ E-mail : loong.jessicalianita@gmail.com
}

\begin{abstract}
Own-Source Revenue is a source of regional financial and funding of the government. One of the revenues comes from local tax, which is the tax on utilization of mineral group $C$, especially in Sangihe islands regency. This research was conducted to find out how big the growth rate and contribution of mineral group $C$-tax to original income in regency of Sangihe islands in 2011-2016. This research had used a qualitative approach to the type of descriptive research, namely analyzing the data target and realization of utilization of mineral group $C$ in 2011 using the ratio of growth rate and contribution.

The results showed the acceptance realization of mineral group $C$-tax still fluctuate or vary. The growth rate of mineral group $C$-tax in Sangihe islands regency with fluctuate number and tends to be negative. The average growth rate of mineral group $C$-tax reached $10.53 \%$. The growth rate considered to be unsuccessful, this is due to lack of public awareness in paying local taxes, especially mineral group $C$-tax. Mineral group $C$ ia also provide a very low contribution. The contribution of mineral group $C$-tax as the own-source revenue for the last six years is enough maximal and included in the criteria of "moderate" contribution. The result of the analysis obtained an average contribution rate of only $27.28 \%$. Keywords : minnerals group c-tax, own-source revenue, growth rate and contribution
\end{abstract}

\section{PENDAHULUAN}

Negara Republik Indonesia merupakan Negara Hukum berdasarkan Pancasila dan Undang - Undang Dasar 1945 yang menjunjung tinggi hak dan kewajiban setiap masyarakat. Negara menempatkan perpajakan sebagai perwujudan salah satu kewajiban kenegaraan dalam rangka kegotong-royongan nasional sebagai peran serta aktif masyarakat dalam membiayai pembangunan.

Soemitro dalam (Mardiasmo, 2016:1) Pajak adalah iuran rakyat kepada kas negara berdasarkan undang-undang (yang dapat dipaksakan) denga tiada mendapat jasa timbal (kontraprestasi) yang langsung dapat ditunjukkan dan yang digunakan untuk membayar pengeluaran umum.

Menurut Peraturan Daerah Kabupaten Kepulauan Sangihe Nomor 3 tahun 2010 tentang Pajak Daerah. Pajak Daerah merupakan sumber pendapatan Pajak Daerah dalam rangka menunjang Peningkatan Otonomi Daerah yang nyata, dinamis, serasi dan bertanggung jawab, guna meningkatkan Penerimaan Daerah berbasis Ekonomi Kerakyatan sehingga perlu diatur dalam peraturan Daerah.

Sesuai dengan Undang-Undang Nomor 28 Tahun 2009 Pasal 1 angka 29 dan 30, Pajak Pengambilan Bahan Galian Golongan $\mathrm{C}$ atau Pajak Mineral bukan Logam dan Batuan adalah pajak atas kegiatan pengambilan bahan galian golongan $\mathrm{C}$ (Pajak Mineral bukan Logam dan Batuan), baik dari sumber alam di dalam dan atau permukaan bumi untuk dimanfaatkan. Sedangkan yang dimaksud dengan mineral bukan logam dan batuan (galian C) adalah mineral bukan logam dan batuan 
sebagaimana dimaksud didalam peraaturan perundang-undangan dibidang mineral dan batu bara.

Pajak Mineral bukan Logam dan Batuan merupakan pengganti dari Pajak Pengambilan Bahan Galian Golongan $\mathrm{C}$ yang semula diatur dalam Undang-Undang Nomor 18 Tahun 1997 dan Undang-Undang Nomor 34 Tahun 2000 (Marihot Pahala Siahaan, 2013:433). Pajak Pengambilan Bahan Galian Golongan C (Pajak Mineral bukan Logam dan Batuan) di atur menurut peraturan daerah kabupaten/kota. Di Kabupaten Kepulauan Sangihe diatur dalam peraturan daerah NO. 3 Tahun 2010 tentang Pajak Daerah.

Objek bahan galian golongan $\mathrm{C}$ atau Pajak Mineral bukan Logam dan Batuan di sektor pertambangan di Kabupaten Kepulauan Sangihe adalah penambangan batu, pasir dan kerikil yang berasal dari sungai. Batu adalah kumpulan-kumpulan dari mineral-mineral yang sudah dalam keadaan membeku/keras. Pasir merupakan butirbutir yang halus dan merupakan lapisan tanah atau timbunan kersik halus. Sedangkan kerikil adalah butiran batu yang lebih besar dari pada pasir tetapi lebih besar dari pada kerikil,berukuran kira-kira sebesar biji nangka. Batu, Pasir dan kerikil banyak dimanfaatkan sebagai bahan bangunan.

Penerimaan pajak pengambilan bahan galian golongan $\mathrm{C}$ merupakan sumber potensial bagi Kabupaten Kepulauan Sangihe. Dimana penerimaan pajak pengambilan bahan galian golongan $\mathrm{C}$ tercapai dari target yang ditetapkan oleh Dinas Pendapatan, Pengelolaan Keuangan dan Aset, tetapi terjadi fluktuasi karena kurangnya pemahaman dari wajib pajak dalam melaporkan hasil pencairan dana dari pengambilan bahan galian golongan $\mathrm{C}$, yang dananya telah dicairkan di Provinsi Sulawesi Utara, dalam hal ini wajib pajak tidak kembali lagi melapor di Dinas Pendapatan, Pengelolaan Keuangan dan Aset Kabupaten Kepulauan Sangie.

Penerimaan pajak pengambilan bahan galian golongan $\mathrm{C}$ di Kabupaten Kepulauan Sangihe selama 6 tahun mengalami penurunan dari Rp. 1.367.385.900 pada tahun 2011 menjadi Rp. 795.598.320 pada tahun 2016.

Berdasarkan uraian tersebut maka mendorong penulis untuk melakukan penelitian dengan judul "Analisis Tingkat Pertumbuhan Penerimaan Pajak Pengambilan Bahan Galian Golongan C di Kabupaten Kepulauan Sangihe".

\subsection{Rumusan Masalah}

1. Bagaimana Tingkat Pertumbuhan Penerimaan Pajak Pengambilan Bahan Galian Golongan C di Kabupaten Kepulauan Sangihe?

2. Berapa besar kontribusi Pajak Daerah terhadap PAD?

\subsection{Tujuan Penelitian}

Adapun tujuan yang ingin dicapai dalam penelitian ini adalah :

1. Untuk mengetahui Tingkat Pertumbuhan penerimaan pajak pengambilan bahan galian golongan C di Kabupaten Kepulauan Sangihe.

2. Untuk menghitung kontribusi Pajak Daerah terhadap PAD.

\subsection{Manfaat Penelitian}

Dalam penelitian ini manfaat yang dapat diberikan ada 2 macam, yaitu manfaat secara teoritis dan manfaat secara praktis :

1. Manfaat Teoritis

Memberi manfaat bagi perkembangan pengetahuan mengenai penerimaan pajak khususnya pajak pengambilan bahan galiangolongan c (pajak mineral bukan 
logam dan batuan), dan dapat menjadi referensi bagi peneliti lain untuk mengadakan penelitian.

2. Manfaat Praktis

Manfaat praktis yang di maksud adalah untuk:

a. Bagi Pemerintah, dengan adanya penelitian ini dapat diharapkan dapat menjadi bahan pertimbangan dalam menentukan kebijakan strategis sekaligus koreksi kinerjanya.

b. Bagi Penulis, sebagai sarana untuk menerapkan ilmu pengetahuan yang telah diperoleh selama kuliah, melalui peneliti yang telah dilakukan.

\section{TINJAUAN PUSTAKA}

\subsubsection{Pengertian Akuntansi}

Akuntansi merupakan suatu seni pencatatan, penggolongan dan pengikhtisaran dengan cara tertentu dan dalam ikuran moneter transaksi dan kejadian yang umumnya bersifat keuangan dan mentafsirkan hasil-hasilnya (Indudewi,2012:1).

Secara umum Akuntansi dapat didefinisikan sebagai sebuah sistem informasi yang memberikan laporan kepada para pengguna informasi akuntansi atau kepada pihak - pihak yang memiliki kepentingan (stakeholder) terhadap hasil kinerja \& kondisi perusahaan (Herry, 2014:1)

\subsubsection{Pengertian Akuntansi Pajak}

Akuntansi pajak adalah akuntansi yang berkaitan dengan perhitungan perpajakan dan mengacu pada peraturan dan perundang-undangan perpajakan beserta aturan pelaksanaannya. Fungsi akuntansi pajak adalah mengolah data kuantitatif yang akan digunakan untuk menyajikan laporan keuangan yang memuat perhitungan perpajakan.

Dalam menerapkan besarnya pajak terutang tetap mendasarkan laporan keuangan yang disusun oleh perusahaan, mengingat dalam ketentuan peraturan perundang - undangan perpajakan terdapat aturan - aturan khusus yang berkaitan dengan akuntansi, yaitu masalah konsep transaksi dan peristiwa keuangan, metode pengukurannya, serta pelaporannya yang ditetapkan dengan undang - undang (Waluyo, 2012:35).

\subsubsection{Pengertian Pajak}

Menurut Undang - Undang Nomor 16 tahun 2009 tentang perubahan keempat atas Undang - Undang Nomor 6 tahun 1983 tentang ketentuan Umum dan Tata Cara Perpajakan pada pasal 1 ayat 1 berbunyi pajak adalah kontribusi wajib kepada Negara yang terutang oleh orang pribadi atau badan yang bersifat memaksa berdasarkan Undang - Undang, dengan tidak mendapatkan imbalan secara langsung dan digunakan untuk keperluan Negara bagi sebesar - besarnya kemakmuran rakyat.

Menurut Prof. Dr. Rochmat Soemitro, SH, pajak adalah iuran rakyat kepada kas Negara berdasarkan undang - undang (yang dapat dipaksakan) dengan tiada mendapat jasa timbal (kontraprestasi) yang langsung dapat ditunjukkan dan yang digunakan untuk membayar pengeluaran umum (Thomas Sumarsan, 2013:3).

\subsubsection{Fungsi Pajak}

Menurut Mardiasmo (2016), terdapat dua fungsi pajak yaitu budgetair dan regulerend. Penjelasannya adalah sebagai berikut. 
1. Fungsi Budgetair, yaitu pajak sebagai sumber dana bagi pemerintah untuk membiayai pengeluaran-pengeluarannya.

2. Fungsi Regulerend atau fungsi mengatur, pajak sebagai alat untuk mengatur atau melaksanakan kebijakan pemerintah dalam bidang sosial dan ekonomi.

Contoh:

a) Pajak yang tinggi dikenakan terhadap minuman keras untuk mengurangi konsumsi minuman keras.

b) Pajak yang tinggi dikenakan terhadap barang-barang mewah untuk mengurangi gaya hidup konsumtif.

c) Tarif pajak untuk ekspor 0\% untuk mendorong ekspor produk Indonesia di pasar dunia.

\subsubsection{Asas-Asas Perpajakan}

Menurut Adam Smith sebagaimana dikutip oleh Nurmantu (2013), mengemukakan 4 (empat) asas yang disebut sebagai four maxims atau four canons, diantaranya adalah equity, certainty, convenience, dan efficiency, yang akan dijelaskan dibawah ini :

(1) Equity adalah supaya tekanan pajak antara subjek pajak masing-masing hendaknya dilakukan seimbang dengan kemampuannya, yaitu seimbang dengan penghasilan yang dinikmatinya dibawah perlindungan negara.

(2) Certainty, dimaksudkan supaya pajak yang harus dibayar seseorang harus terang dan pasti tidak dapat dimulur-mulur atau ditawar-tawar.

(3) Convenience, dimaksudkan supaya dalam memungut pajak pemerintah hendaknya memperhatikan saat-saat yang paling baik bagi pembayar pajak.

(4) Efficiency, dimaksudkan supaya pemungutan pajak hendaknya dilaksanakan sehemat-hematnya, jangan sampai biaya-biaya memungut lebih tinggi daripada pajak yang dipungut.

\subsubsection{Sistem Pemungutan Pajak}

Sistem pemungutan pajak menurut Mardiasmo (2016), terbagi menjadi Official Assesment System, Self Assesment System dan With Holding Tax System. Penjelasan dari ketiga sistem pemungutan pajak tersebut adalah sebagai berikut.

(1) Official Assesment System adalah suatu sistem pemungutan yang memberi wewenang kepada pemerintah (fiskus) untuk menentukan besarnya pajak yang terutang oleh wajib pajak. Ciri-cirinya adalah wewenang untuk menentukan besarnya pajak terutang pada fiskus; wajib pajak berrsifat pasif; utang pajak timbul setelah dikeluarkan surat ketetapan pajak oleh fiskus.

(2) Self Assesment System adalah suatu sistem pemungutan pajak yang memberi wewenang kepada wajib pajak untuk menentukan sendiri besarnya pajak yang terutang. Ciri-cirinya adalah wewenang untuk menentukan besarnya pajak terutang ada pada wajib pajak sendiri; wajib pajak aktif, mulai dari menghitung, menyetor, dan melaporkan sendiri pajak yang terutang; fiskus tidak ikut campur, hanya mengawasi.

(3) With Holding Tax System adalah suatu sistem pemungutan pajak yang memberi wewenang kepada pihak ketiga (bukan fiskus dan bukan wajib pajak yang bersangkutan). Ciri-cirinya adalah wewenang menentukan besarnya pajak terutang ada pada pihak ketiga, pihak selain fiskus dan wajib pajak itu sendiri. 


\subsubsection{Jenis Pajak}

Menurut Mardiasmo (2016), pajak dapat diklasifikasikan menurut golongan yang terdiri dari pajak langsung dan tidak langsung, berdasarkan sifatnya terdiri dari pajak subjektif dan pajak objektif, sedangkan menurut lembaga pemungutannya pajak terdiri pajak pusat dan pajak daerah, yaitu :

1) Menurut golongannya

a) Pajak Langsung, yaitu pajak yang harus dipikul sendiri oleh wajib pajak dan tidak dapat dibebankan atau dilimpahkan kepada orang lain. Contoh: Pajak Penghasilan (PPh).

b) Pajak Tidak Langsung, yaitu pajak yang pada akhirnya dapat dibebankan atau dilimpahkan kepada orang lain. Contoh: Pajak Pertambahan Nilai (PPN).

2) Menurut Sifatnya

a) Pajak subjektif, pajak yang berpangkal atau berdasarkan pada subyeknya, dalam arti memperhatikan keadaan diri wajib pajak. Contoh: Pajak Penghasilan $(\mathrm{PPh})$.

b) Pajak Objektif, pajak yang berpangkal pada obyeknya, tanpa memperhatikan keadaan diri wajib pajak. Contoh: Pajak Pertambahan Nilai (PPN) dan Pajak Penjualan Atas Barang Mewah (PPnBM).

3) Menurut Lembaga Pemungutannya

a) Pajak Pusat, yaitu pajak yang dipungut oleh pemerintah pusat dan digunakan untuk membiayai rumah tangga negara. Contoh: Pajak Penghasilan (PPh), Pajak Pertambahan Nilai (PPN, dan Pajak Penjualan Atas Barang Mewah (PPnBM), Pajak Bumi dan Bangunan (PBB), dan Bea Materai.

b) Pajak Daerah, yaitu pajak yang dipungut oleh pemerintah daerah dan digunakan untuk membiayai rumah tangga daerah. Pajak daerah terdiri atas. :

- Pajak Provinsi, contoh: pajak kendaraan bermotor dan pajak bahan bakar kendaraan bermotor.

- Pajak Kabupaten, contoh: pajak hotel, pajak restoran dan pajak hiburan.

\subsubsection{Tarif Pajak}

Menurut Mardiasmo (2016), tarif pajak terdiri dari :

(1) Tarif sebanding/proporsional

Tarif pajak berupa prosentase yang tetap terhadap berapapun jumlah yang dikenai pajak sehingga pajak yang terutang proporsional terhadap besarnya nilai yang dikenai pajak. Contoh: untuk menyerahkan barang kena pajak di dalam daerah pabean akan dikenakan pajak pertambahan nilai sebesar $10 \%$.

(2) Tarif tetap

Tarif berupa jumlah yang tetap (sama) terhadap berapapun jumlah yang dikenai pajak sehingga besarnya pajak terutang tetap.

Contoh: besarnya tarif bea materai untuk cek dan bilyet giro dengan nilai nominal berapapun adalah Rp 1.000.000,00.

(3) Tarif Progresif

Prosentase tarif yang digunakan semakin besar bila jumlah yang dikenai pajak semakin besar. Contoh: Pasal 17 UU Pajak Penghasilan. 


\subsection{Pendapatan Asli Daerah}

Menurut undang-undang Nomor 33 Tahun 2004, Pendapatan Daerah adalah semua hak daerah yang diakui sebagai penambah nilai kekayaan bersih dalam periode tahun anggaran yang bersangkutan.

Pendapatan Asli Daerah merupakan semua penerimaan yang diperoleh daerah dari sumber-sumber dalam wilayahnya sendiri yang dipunggut berdasarkan peraturan daerah sesuai dengan peraturan perundang-undangan yang berlaku. Pendapatan Asli Daerah merupakan tulang punggung pembiayaan daerah, oleh karenanya kemampuan melaksanakan ekonomi diukur dari besarnya kontribusi yang dapat diberikan oleh pendapatan asli daerah terhadap Anggaran Pendapatan dan Belanja Daerah (APBD) berarti semakin kecil ketergantungan pemerintah daerah terhadap bantuan pemerintah pusat (Indah Rahmawati, 2013).

\subsection{Pajak Daerah}

\subsubsection{Pengertian Pajak Daerah}

Pajak Daerah, yang selanjutnya disebut pajak, adalah kontribusi wajib kepada Daerah yang terutang oleh orang pribadi atau badan yang bersifat memaksa berdasarkan Undang - undang, dengan tidak mendapatkan imbalan secara langsung dan digunakan untuk keperluan Daerah bagi sebesar - besarnya kemakmuran rakyat (Mardiasmo; 2016).

Pajak daerah adalah kontribusi wajib kepada daerah yang terutang oleh orang pribadi atau badan yang bersifat memaksa berdasrkan Undang - Undang, dengan tidak mendapatkan imbalan secara langsung dan digunakan untuk keperluan daerah sebesar - besarnya kemakmuran rakyat (TMbook, 2015 : 442).

\subsection{Pajak Pengambilan Bahan Galian Golongan C atau Pajak Mineral bukan Batuan dan Logam.}

\subsubsection{Pengertian Pajak Galian Golongan $\mathbf{C}$}

Pajak Galian Golongan C atau Pajak Mineral bukan Batuan dan Logam adalah pajak atas kegiatan pengambilan bahan galian golongan $\mathrm{C}$, baik dari sumber alam di dalam dan atau di permukaan bumi (Irwan Wisanggeni,2016:82).

Galian Golongan $\mathrm{C}$ adalah mineral bukan logam dan batuan sebagaimana termasuk dimaksud di dalam peraturan perundang - undangan di bidang mineral dan batubara.

\subsubsection{Subjek Pajak dan Wajib Pajak}

- Subjek Pajak adalah orang pribadi atau badan yang dapat mengambil bahan Galian Golongan $\mathrm{C}$ atau bahan Mineral bukan Logam dan Batuan.

- Wajib Pajak adalah orang pribadi atau badan yang mengambil bahan Galian Golongan $\mathrm{C}$ atau bahan Mineral bukan Logam dan Batuan.

\subsubsection{Sitem Pemungutan Pajak Bahan Galian Golongan $\mathrm{C}$ atau Pajak Mineral bukan Logam dan Batuan}

- Self Assessment sistem, dimana wajib pajak diberikan kepercayaan untuk menghitung, membayar dan melaporkan sendiri jumlah pajak terutangnya atau pajak galian golongan c.

\subsubsection{Dasar Penggenaan Pajak Galian Golongan C atau Pajak Mineral bukan Logam} dan Batuan

- Dasar Penggenaan Pajak Galian golongan C adalah Nilai Jual Hasil Pengambilan Bahan galian Golongan C 
- Nilai Jual Hasil Pengambilan Galian Golongan C dihitung dengan mengalikan volume/tonase hasil pengambilan dengan nilai pasar atau harga standar masing masing jenis galian golongan c atau mineral bukan logam dan batuan.

\subsubsection{Dasar Hukum Pemungutan Pajak Pengambilan Bahan Galian Golongan C atau Pajak Mineral bukan Logam dan Batuan}

Dasar hukum pemungutan Pajak Galian Golongan C pada suatu kabupaten atau kota adalah sebagaiman di bawah ini :

1. Undang - Undang Nomor 28 Tahun 2009 tentang Pajak Daerah dan Retribusi Daerah.

2. Undang - Undang Nomor 34 Tahun 2000 yang merupakan perubahan atas Undang - Undang Nomor 18 Tahun 1997 tentang Pajak Daerah dan Retribusi Daerah.

3. Peraturan Pemerintah Nomor 65 Tahun 2001 tentang Pajak Daerah.

4. Peraturan daerah kabupaten/kota yang mengatur tentang Pajak Pengambilan Bahan Galian Golongan C.

5. Keputusan bupati/walikota yang mengatur tentang Pajak Pengambilan Bahan Galian Golongan Csebagai aturan pelaksanaan Peraturan Daerah tentang Pajak Pengambilan Bahan Galian Golongan C pada kabupaten/kota dimaksud.

\subsubsection{Tarif Pajak Galian Golongan $C$ atau Pajak Mineral bukan Logam dan Batuan}

- Tarif Maksimum untuk pajak galian golongan c sesuai dengan UU No 28 tahun 2009 tentang Pajak Daerah dan Retribusi Daerah adalah sebesar 25\%.

- Tarif pajak yang ditetapkan di Kabupaten Kepulauan Sangihe sesuai dengan Peraturan Daerah tentang Pajak Daerah No 3 tahun 2010 adalah sebesar 20\%.

\section{METODE PENELITIAN}

\subsection{Jenis dan sumber data}

\section{Jenis Data}

Dalam Penelitian ini digunakan jenis penelitian kualitatif dengan metode analisis deskriptif. Penelitian deskriptif adalah penelitian yang berusaha mendeskripsikan suatu gejala, peristiwa, kejadian yang terjadi saat sekarang. Juliansyah Noor (2011:34)

\section{Sumber Data}

\section{Sumber Primer}

Sumber primer adalah sumber data yang secara langsung memberikan data kepada pengumpul data (Sugiyono, 2012 :225). Sumber Primer ini berupa catatan hasil wawancara yang diperoleh melalui wawancara yang dilakukan. Yang menjadi data primer dalam penelitian ini adalah data Penerimaan Pajak Pengambilan Bahan Galian Golongan C yaitu Batu, Pasir dan Krikil.

2. Sumber Sekunder

Sumber data sekunder merupakan sumber data yang tidak memberikan informasi secara langsung kepada pengumpul data. Sumber data sekunder ini dapat berupa hasil pengolahan lebih lanjut dari data primer yang disajikan dalam bentuk lain atau dari orang lain (Sugiyono, 2012:225).

Sumber data sekunder juga berupa media perantara yaitu melalui hasil - hasil penelitian, buku - buku, artike, jurnal dan berbagai publikasi. 


\subsection{Metode analisis}

Metode Analisis yang digunakan adalah Analisis Kontribusi dan Analisis Laju Pertumbuhan Galian Golongan C.

\section{Analisis Laju pertumbuhan}

Analisis yang digunakan untuk mengetahui seberapa besar laju pertumbuhan pajak daerah selama 6 tahun dalam persentase, dapat dihitung dari realisasi jumlah pajak daerah pada tahun tertentu dibandingkan dengan realisasi jumlah pajak daerah pada tahun sebelumnya. Analisis Laju pertumbuhan Pajak Daerah :

$$
\mathrm{Y}=\frac{\mathrm{Y}_{\mathrm{t}}-\mathrm{Y}_{\mathrm{t}-1}}{\mathrm{Y}_{\mathrm{t}-1}} \times \quad 100 \%
$$

Keterangan :

$\mathrm{Y}=$ Laju Pertumbuhan Pajak Galian Golongan C pertahun

$\mathrm{Yt}=$ Realisasi penerimaan Pajak Galian Gol. C yang sah pada tahun tertentu

Yt-1 = Realisasi penerimaan Pajak Galian Gol. C yang sah pada tahun sebelumnya

\section{Analisis Kontribusi}

Analisis kontribusi adalah alat analisis yang digunakan untuk mengetahui seberapa besar kontribusi yang diberikan oleh pajak daerah terhadap Pendapatan Asli Daerah (PAD) Kabupaten Kepulauan Sangihe. Analisis ini dilakukan dengan cara membandingkan realisasi pajak daerah dengan realisasi Pendapatan Asli Daerah (PAD) Kabupaten Kepulauan Sangihe. Adapun rumus yang dapat digunakan yaitu :

$$
\text { Analisis Kontribusi }=\frac{\text { Realisasi Pajak Galian Gol. C }}{\text { Realisasi Penerimaan PAD }} \times 100 \%
$$

\section{HASIL ANALISIS DAN PEMBAHASAN}

\subsection{Hasil analisis}

Perusahaan - perusahaan yang melakukan galian golongan C di Kabupaten Kepulauan Sangihe adalah CV. Dinasti dan PT Gading Murni Perkasa. Berikut ini merupakan peneriman pajak pengambilan bahan galian golongan $\mathrm{C}$ atau Pajak Mineral bukan Logam dan Batuan di Kabupaten Kepulauan Sangihe :

\section{Tabel 1}

Penerimaan Pajak Pengambilan Bahan Galian Golongan C Batu, Pasir dan Krikil (Dalam Rupiah)

\begin{tabular}{|c|c|c|c|}
\hline Tahun & Target & Realisasi & Keterangan \\
\hline $\mathbf{2 0 1 1}$ & 1.250 .000 .000 & 1.367 .385 .900 & \\
\hline $\mathbf{2 0 1 2}$ & 1.250 .000 .000 & 1.093 .845 .750 & \\
\hline $\mathbf{2 0 1 3}$ & 1.400 .663 .220 & 586.251 .208 & \\
\hline $\mathbf{2 0 1 4}$ & 1.400 .663 .220 & 700.769 .500 & \\
\hline $\mathbf{2 0 1 5}$ & 1.500 .000 .000 & 1.774 .058 .300 & BATU \\
\hline \multirow{2}{*}{$\mathbf{2 0 1 6}$} & 1.200 .000 .000 & 449.486 .454 & PASIR \& KRIKIL \\
\cline { 2 - 4 } & 2.000 .000 .000 & 346.111 .866 & \\
\hline
\end{tabular}

Sumber : Dinas Pendapatan, Pengelolaan Keuangan dan Aset 
Dari tabel di atas penambangan batu, pasir dan krikil di Kabupaten Kepulauan Sangihe di tahun 2012 - 2014 dan tahun 2016 tidak mencapai target yang telah ditetapkan oleh dinas pendapatan, pengelolaan keuangan dan asset. Target yang ditetapkan dari tahun ke tahun naik.

Tahun 2011, target yang di tetapkan sebesar Rp. 1.2M dan yang terealisasi dari galian golongan c sebesar Rp. 1.3M, tahun 2012 target yang ditetapkan sebesar Rp. 1.2M dan yang terealisasi dari galian golongan C sebesar Rp. 1M, tahun 2013 target yang ditetapkan sebesar Rp. 1.4M dan yang terealisasi dari galian golongan c sebesar Rp. 586juta, tahun 2014 target yang telah ditetapkan sebesar Rp.1.4M dan yang terealisasi dari galian golongan c sebesar Rp.700juta, tahun 2015 target yang telah ditetapkan sebesar Rp. $1.5 \mathrm{M}$ dan yang terealisasi dari galian golongan c sebesar Rp.1.7M, sedangkan tahun 2016 target yang telah ditetapkan dari batu, pasir dan krikil telah dipisahkan, target yang telah ditetapkan untuk Batu sebesar Rp.1.2M dan yang terealisasi dari galian golongan c sebesar Rp. 449juta, dan target yang telah ditetapkan untuk pasir \& krikil sebesar Rp. $2 \mathrm{M}$ dan yang terealisasi dari galian golongan c sebesar Rp. 346juta.

Dari hasil data ini juga terjadi fluktuasi terhadap penerimaan pajak pengambilan bahan galian golongan $\mathrm{C}$ dan juga penerimaan pajak galian golongan $\mathrm{C}$ tidak mencapai target di Kabupaten Kepulauan Sangihe.

\section{Tabel 2}

Penerimaan Pendapatan Asli Daerah di Kabupaten Kepulauan Sangihe (Dalam Rupiah)

\begin{tabular}{|c|c|c|c|}
\hline Tahun & Target & Realisasi & Selisih \\
\hline 2011 & 2.223 .812 .000 & 3.500 .252 .000 & - \\
\hline 2012 & 2.543 .452 .000 & 3.343 .960 .000 & 156.292 .000 \\
\hline 2013 & 3.145 .650 .000 & 3.384 .920 .000 & 40.960 .000 \\
\hline 2014 & 3.500 .800 .000 & 5.387 .370 .000 & 2.002 .450 .000 \\
\hline 2015 & 3.500 .800 .000 & 4.527 .890 .000 & 859.480 .000 \\
\hline 2016 & 3.700 .975 .000 & 3.400 .839 .000 & 1.127 .051 .000 \\
\hline
\end{tabular}

Sumber : (Dinas Pendapatan, Pengelolaan Keuangan dan Aset, 2017)

Sama halnya dengan penerimaan Pajak Pengambilan Bahan Galian Golongan C, penerimaan Pendapatan Asli Daerah dari tahun 2011-2016 setiap tahunnya mengalami fluktuasi. Pada tahun 2011 realisasi Pendapatan Asli Daerah mencapai Rp. 3.500.252.000, tahun 2012 turun sebesar Rp. 156.292.000 menjadi Rp.3.343.960.000, tahun 2013 naik sebesar Rp.40.960.000 menjadi RP.3.384.920.000, tahun 2014 naik sebesar Rp.2.002.450.000 menjadi Rp.5.387.370.000, tahun 2015 turun sebesar Rp.859.480.000 menjadi Rp.4.527.890.000 dan pada tahun 2016 turun sebesar Rp.1.127.051.000 menjadi Rp.3.400.839.000.

Dari data diatas, dapat disimpulkan bahwa jumlah Realisasi Pendapatan Asli Daerah tertinggi terjadi pada tahun 2014 sebesar Rp.5.387.370.000 dan terendah terjadi pada tahun 2012 sebesar Rp.3.343.960.000. 


\subsection{Pembahasan}

\section{Analisis Tingkat Pertumbuhan Pajak Galian Golongan C dan Laju Pertumbuhan Pendapatan Asli Daerah.}

Analisis yang digunakan untuk mengetahui seberapa besar tingkat pertumbuhan Pajak Galian Golongan C dan Pendapatan Asli Daerah selama 6 tahun dalam persentase, dapat dihitung dari realisasi penerimaan pajak Galian Golongan C pada tahun tertentu dibandingkan dengan realisasi penerimaan pajak Galian Golongan $\mathrm{C}$ pada tahun sebelumnya. Begitu juga dengan Tingkat pertumbuhan Pendapatan Asli Daerah. Mengukur tingkat pertumbuhan Pajak Galian Golongan C dan Pendapatan Asli Daerah digunakan rumus sebagai berikut :

$$
\mathrm{Y}=\frac{\mathrm{Y}_{\mathrm{t}}-\mathrm{Y}_{\mathrm{t}-1}}{\mathrm{Y}_{\mathrm{t}-1}} \times \quad 100 \%
$$

Untuk mengetahui tingkat pertumbuhan Pajak Galian Golongan C di Kabupaten Kepulauan Sangihe, yaitu dari tahun 2011 - 2016 dapat dilihat pada tabel berikut :

Tabel 3

Tingkat Pertumbuhan Pajak Galian Golongan C (Dalam Rupiah)

\begin{tabular}{|c|c|c|c|}
\hline Tahun & $\mathrm{Y}_{\mathrm{t}}$ & $\mathrm{Y}_{\mathrm{t}-1}$ & $\begin{array}{c}\text { Tingkat } \\
\text { Pertumbuhan (Y) }\end{array}$ \\
\hline 2011 & 1.367 .385 .900 & - & - \\
\hline 2012 & 1.093 .845 .750 & 1.367 .385 .900 & $-20,00 \%$ \\
\hline 2013 & 586.251 .208 & 1.093 .845 .750 & $-46,40 \%$ \\
\hline 2014 & 700.769 .500 & 586.251 .208 & $19,53 \%$ \\
\hline 2015 & 1.774 .058 .300 & 700.769 .500 & $153,16 \%$ \\
\hline 2016 & 795.598 .320 & 1.774 .058 .300 & $-55,15 \%$ \\
\hline \multicolumn{4}{|c|}{ Rata-Rata } \\
\hline
\end{tabular}

\section{Sumber : (data diolah, 2017)}

Dari hasil penelitian yang dilakukan oleh peneliti bahwa tingkat laju pertumbuhan pajak Galian Golongan C di Kabupaten Kepulauan Sangihe mengalami fluktuasi atau naik turun dan cenderung negatif atau dengan kriteria "tidak berhasil". Hal ini disebabkan karena kurangnya kesadaran wajib pajak untuk membayar pajak khususnya pajak Galian Golongan C sehingga mengakibatkan penerimaan pajak galian golongan $\mathrm{c}$ tidak mencapai target dari yang telah ditetapkan sebelumnya. Hal ini juga terjadi karena kurangnya pemahaman wajib pajak dalam melaporkan setiap pengambilan bahan galian golongan $\mathrm{C}$ di Dinas Pendapatan, Pengelolaan Keuangan dan Aset di Kabupaten Kepulauan Sangihe yang dananya telah di cairkan di Provinsi Sulawesi Utara, dalam hal ini wajib pajak tidak kembali lagi melapor di DPPKAD Kabupaten Kepulauan Sangihe. Dengan rata-rata pertumbuhan pajak Galian Golongan C mencapai 10,53\%.

Untuk mengetahui tingkat pertumbuhan Pendapatan Asli Daerah di Kabupaten Kepulauan Sangihe, yaitu dari tahun 2011 - 2016 dapat dilihat pada table berikut : 


\section{Tabel 4}

Tingkat Pertumbuhan Pendapatan Asli Daerah

(Dalam Rupiah)

\begin{tabular}{|c|c|c|c|}
\hline Tahun & $\mathrm{Y}_{\mathrm{t}}$ & $\mathrm{Y}_{\mathrm{t}-1}$ & $\begin{array}{c}\text { Tingkat } \\
\text { Pertumbuhan } \\
(\mathrm{Y})\end{array}$ \\
\hline 2011 & 3.500 .252 .000 & - & - \\
\hline 2012 & 3.343 .960 .000 & 3.500 .252 .000 & $-4,46 \%$ \\
\hline 2013 & 3.384 .920 .000 & 3.343 .960 .000 & $1,22 \%$ \\
\hline 2014 & 5.387 .370 .000 & 3.384 .920 .000 & $59,16 \%$ \\
\hline 2015 & 4.527 .890 .000 & 5.387 .370 .000 & $-15,95 \%$ \\
\hline 2016 & 3.400 .839 .000 & 4.527 .890 .000 & $-24,89 \%$ \\
\hline \multicolumn{4}{|c|}{ Rata-Rata } \\
\hline
\end{tabular}

Sumber : (data diolah, 2017)

Dari tabel di atas menjelaskan bahwa tingkat pertumbuhan pajak Galian Golongan C di Kabupaten Kepulauan Sangihe mengalami fluktuasi atau naik turun dan cenderung negatif. Rata-rata tingkat pertumbuhan Pendapatan Asli Daerah di Kabupaten Kepulauan Sangihe adalah 15,08\%

\section{Analisis Kontribusi Pajak Bahan Galian Golongan C terhadap PAD}

Rumus Analisis Kontribusi :

$$
\text { Analisis Kontribusi }=\frac{\text { Realisasi Pajak Galian Gol. C }}{\text { Realisasi Penerimaan PAD }} \times 100 \%
$$

\section{Tabel 5}

\section{Analisis Kontribusi Pajak Bahan Galian Golongan C Terhadap PAD}

\begin{tabular}{|c|c|c|}
\hline Tahun & Presentase Kontribusi & Kriteria \\
\hline $\mathbf{2 0 1 1}$ & $39,06 \%$ & Cukup \\
\hline $\mathbf{2 0 1 2}$ & $32,71 \%$ & Cukup \\
\hline $\mathbf{2 0 1 3}$ & $17,32 \%$ & Kurang \\
\hline $\mathbf{2 0 1 4}$ & $13,01 \%$ & Kurang \\
\hline $\mathbf{2 0 1 5}$ & $38,18 \%$ & Cukup \\
\hline $\mathbf{2 0 1 6}$ & $23,39 \%$ & Sedang \\
\hline
\end{tabular}

Sumber : (data diolah, 2017) 


\section{Tabel 6}

Kontribusi Pajak Bahan Galian Golongan C Terhadap Pendapatan Asli Daerah

Di Kabupaten Kepulauan Sangihe

\begin{tabular}{|c|c|c|c|c|}
\hline Tahun & $\begin{array}{c}\text { Realisasi Pajak } \\
\text { Galian Golongan C }\end{array}$ & Realisasi PAD & Kontribusi & Kriteria \\
\hline 2011 & 1.367 .385 .900 & 3.500 .252 .000 & $39,06 \%$ & Cukup \\
\hline 2012 & 1.093 .845 .750 & 3.343 .960 .000 & $32,71 \%$ & Cukup \\
\hline 2013 & 586.251 .208 & 3.384 .920 .000 & $17,32 \%$ & Kurang \\
\hline 2014 & 700.769 .500 & 5.387 .370 .000 & $13,01 \%$ & Kurang \\
\hline 2015 & 1.774 .058 .300 & 4.527 .890 .000 & $38,18 \%$ & Cukup \\
\hline 2016 & 795.598 .320 & 3.400 .839 .000 & $23,39 \%$ & Sedang \\
\hline \multicolumn{3}{|c|}{ Rata-Rata } & $27,28 \%$ & \\
\hline
\end{tabular}

Sumber : (data diolah, 2017)

Dari tabel 4.9 tingkat presentase kontribusi untuk tahun 2011 sebesar 39,06\%, tahun 2012 sebesar 32,71\%, tahun 2013 sebesar 17,32\%, tahun 2014 sebesar 13,01\%, tahun 2015 sebesar 38,18\% dan tahun 2016 sebesar 23,39\%. Kontribusi terbesar terjadi pada tahun 2011 yaitu menyumbang $39,06, \%$, sedangkan terendah terjadi pada tahun 2014 yaitu sebesar 13,01\%. Berdasarkan kriteria penilaian kontribusi, Pajak Galian Golongan C sebagai sumber Pendapatan Asli Daerah masuk kriteria "Sedang" dengan presentase rata-rata $27,28 \%$.

\section{KESIMPULAN DAN SARAN}

\subsection{Kesimpulan}

Berdasarkan hasil penelitian dan pembahasan pada bab sebelumnya, maka dapat diambil kesimpulan sebagai berikut :

1. Penerimaan Pajak Galian Golongan C di Kabupaten Kepulauan Sangihe dalam kurun waktu enam tahun dari tahun 2011-2016 tidak terus mengalami peningkatan melainkan berubah-ubah atau mengalami fluktuasi. Tahun $2011 \mathrm{Rp}$. 1.367.385.900, tahun 2012 mengalami penurunan menjadi Rp. 1.093.845.750, tahun 2013 juga mengalami penurunan menjadi Rp. 586.251.208, tahun 2014 naik menjadi Rp. 700.769.500, tahun 2015 naik menjadi Rp. 1.774.058.300 dan tahun 2016 kembali mengalami penurunan menjadi Rp. 795.598.320

2. Tingkat Pertumbuhan Pajak Galian Golongan $\mathrm{C}$ dan Pertumbuhan Pendapatan Asli Daerah mengalami fluktuasi atau berubah-ubah dan cenderung negatif. Ratarata pertumbuhan Pajak Galian Golongan C mencapai 10,53\%. Begitu juga dengan pertumbuhan Pendapatan Asli Daerah mengalami naik turun atau berubahubah dan cenderung negatif dengan rata-rata mencapai $(15,08 \%)$.

Pertumbuhan Pajak Galian Golongan C terbesar terjadi pada tahun 2015 yaitu sebesar 153,16\%, terendah pada tahun 2016 yaitu sebesar $-55,15 \%$. Sedangkan laju pertumbuhan Pendapatan Asli Daerah terbesar terjadi pada tahun 2014 yaitu sebesar 59,16\% dan yang terendah pada tahun 2016 yaitu sebesar -24,89\%.

3. Kontribusi Pajak Galian Golongan C sebagai sumber Pendapatan Asli Daerah setiap tahun masing-masing adalah 2011 (39,06\%), 2012 (32,71\%), 2013 $(17,32 \%), 2014(13,01 \%), 2015$ (39,18\%), dan 2016 (23,39\%). Kontribusi terbesar terjadi pada tahun 2011 yaitu menyumbang 39,06\%, sedangkan terendah terjadi pada tahun 2016 yaitu sebesar 23,39\%.

Kontribusi Pajak Galian Golongan C sebagai sumber Pendapatan Asli Daerah selama enam tahun terakhir dinilai cukup maksimal dan masuk dalam kriteria 
kontribusi "sedang". Hasil analisis diperoleh tingkat kontribusi rata-rata hanya sebesar $27,28 \%$.

\subsection{Saran}

1. Memberikan sanksi tegas kepada Wajib Pajak yang tidak memenuhi kewajiban yang semestinya.

2. Dilaksanakan pendataan ulang Wajib Pajak secara lebih akurat agar penerimaan Pajak Pengambilan Bahan Galian Golongan C dapat diperoleh secara maksimal dan meningkatkan penerimaan Pajak Galian Golongan C di Kabupaten Kepulauan Sangihe.

\section{DAFTAR PUSTAKA}

Arif Setiawan, 2009, Analisis Efektivitas Penerimaan Pajak Pengambilan dan Pengolahan Baan Galian Golongan C Terhadap Pendapatan Asli Daerah Kabupaten BOYOLALI Tahun 2006-2008, Jurnal Universitas Sebelas Maret Surakarta

Abdul Hakim, Andy Fefta Wijaya, dan Ruth Nur Pratiwi, 2015, The Performance of Revenue Office in the Perspective of New Public Management - (Study on Performance of Local Tax Management in Makassar, Indonesia), International Journal of Applied Sociology, Faculty of Administrative Science, University of Brawijaya, Malang, Indonesia, Hal.57-62

Ali Amin, 2015, Model Peningkatan Penerimaan Pajak Mineral bukan Logam dan Batuan di Kabupaten Kubu Raya, Jurnal Ekonomi Daerah

Dian Indudewi, 2012, Pengaruh Kejelasan Sasaran Anggaran, Pengendalian Akuntansi, Dan Sistem Pelaporan Terhadap Akuntabilitas Kinerja Instansi Pemerintah Kabupaten Brebes, Jurnal Universitas Semarang.

Grace N. Ofoegbu, David O. Akwu dan Oliver O, 2016, Empirical Analysis Of Effect Of Tax Revenue On Economic Development Of Nigeria. International Journal of Asian Social Science, ISSN 2224-444, Vol. 6(10), Hal. 604-613

H. Abd. Rachim A.F, 2015, Analyzing Local Revenue in Local Otonomy Implementation towards Self-Reliance of Samarinda Municipality. International Journal of Business Management and Economic Research (IJBMER), ISSN 2229-6247, Vol. 6(6), Hal.436-441

Herry, 2014, Akuntansi Pajak, GRASINDO, Jakarta

Irwan Wisanggeni, 2015, Pajak Di Beragam Sektor Usaha, PT Indeks, Jakarta Barat

Imelda Kurniawan, 2013, Analisis Efektifitas dan Kontribusi Penerimaan Pajak Pengambilan Bahan Galian Golongan C Terhadap Pendapatan Asli Daerah (PAD) Pada Dinas Pendapatan Daerah Kabupaten Kediri, Jurnal Universitas Islam Kediri.

Indah Rahmawati, 2013, Analisis Potensi Penerimaan Pajak Mineral Bukan Logam dan Batuan Sebagai Sumber Pendapatan Asli Daerah di Kabupaten Gresik, Jurnal Universitas Brawijaya

James Abiola dan Moses Asiweh, 2012, Impact of Tax Administration on Government Revenue in a Developing Economy - A Case Study of Nigeria, International Journal of Business and Social Science, Vol.3 No.8, Hal.99-103 
Jessica Rumengan, 2015, Efektivitas Pajak Pengambilan dan Pengolahan Bahan Galian Mineral Bukan Logam dan Batuan Di Kabupaten Minahasa Selatan, Jurnal Universitas Sam Ratulangi

Mardiasmo, 2016, Perpajakan Edisi Revisi, Yogyakarta: Andi

Marihot Pahala Siahaan, 2013, Pajak Daerah \& Retribusi Daerah Edisi Revisi, PT Rajagrafindo Persada, Jakarta

Megasilvia Windy Mintahari, 2016, Analisis Kontribusi Pajak Restoran Terhadap Pendapatan Asli Daerah (PAD) Kabupaten Minahasa Selatan Tahun 20122014, Jurnal Universitas Sam Ratulangi

Nana Syaodih Sukmadinata, 2011, Metode Penelitian Pendidikan, Bandung : PT Remaja Rosdakarya.

Ni Ketut Sari Adnyani, 2014, Correlation Analysis Between Improvement Tax With Tourism Development In The Lovina Singaraja Area (Case Study In The Buleleng District), International Journal of Business, Economics and Law, ISSN 2289-1552, Vol.4, Hal.35-40

Ni Kadek Pebriani, 2017, Kontribusi dan Efektivitas Pajak Galian Golongan C Pada Pendapatan Asli Daerah Kabupaten Karangasem, Jurnal Universitas Pendidikan Ganesha Singaraja, Indonesia.

Pamela Indira Lasut, 2014, Analisis Efektivitas Penerimaan Pajak Pengambilan dan Pengolahan Mineral Bukan Logam dan Batuan Sebagai Sumber Pendapatan Asli Daerah Kota Tomohon, Jurnal Universitas Sam Ratulangi Manado

Pemerintah Republik Indonesia, Peraturan Daerah Kabupaten Kepulauan Sangihe No. 4 Tahun 2009 tentang Pertambangan Mineral dan Batubara Negara Republik Indonesia. Undang-Undang No. 3 Tahun 2010 tentang Pajak Daerah.

Pemerintah Republik Indonesia, Undang - Undang Nomor 34 Tahun 2000 yang merupakan perubahan atas Undang - Undang Nomor 18 Tahun 1997 tentang Pajak Daerah dan Retribusi Daerah.

Pemerintah Republik Indonesia, Undang-Undang Nomor 32 Tahun 2004 tentang Pemerintahan Daerah.

Pemerintah Republik Indonesia, Tahun 2009 Nomor 130, Undang-Undang Nomor 28 Tahun 2009 tentang Pajak Daerah dan Retribusi Daerah.

Pemerintah Republik Indonesia, Undang - Undang Nomor 16 tahun 2009 tentang perubahan keempat atas Undang - Undang Nomor 6 tahun 1983 tentang ketentuan Umum dan Tata Cara Perpajakan.

Ridha Noor Widowati dan Dhiah Fitrayati, 2014, Analisis Efektivitas Potensi Pemungutan Pajak Mineral Bukan Logam dan Batuan di Kabupaten Bojonegoro, Jurnal Universitas Negeri Surabaya

Suwardjono, 2013, Pengantar Akuntansi, BPFE-Yogyakarta

Syaiful Bahri, 2016, Pengantar Akuntansi, Yogyakarta, CV. ANDI OFFSET

Santi Riogilang, 2011, Analisis Efektivitas Pemungurtan Pajak Bahan Galian Golongan C Berdasarkan Sistem Ketetapan Pajak serta Kontribusinya terhadap Pendapan Asli Daerah Kabupaten Minahasa, Jurnal Universitas Sam Ratulangi.

Syafri Nurmantu, 2013, Pengantar Perpajakan, Jakarta : Granit

Simamora, 2013, Akuntansi Manajemen, Jakarta: Salemba Empat

Supramono \& Theresia Woro Damayanti, 2015, Perpajakan Indonesia, CV. ANDI OFFSET

Sugiyono, 2012, Memahami Penelitian Kualitatif, Bandung : ALFABETA 
Thomas Sumarsan, 2013, Perpajakan Indonesia, Edisi Ketiga, PT Indeks, Jakarta Barat.

TMbooks, 2015, Perpajakan Indonesia, Yogyakarta, CV. ANDI OFFSET

V. Wiratna Sujarweni, 2014, Metodologi Penelitian, Yogyakarta : Pustaka Baru Press

Waluyo, 2012, Akuntansi Pajak, Edisi 4, Jakarta : Salemba Empat

Yesika Putri, 2013, Analisis Penerimaan Pajak Pengambilan Bahan Galian Golongan

C di Kantor Dinas Pendapatan Daerah Kabupaten Kampar, Jurnal Universitas Islam Negeri Sultan Sarif Kasim Riau Pekanbaru. 